\title{
Bronchoalveolar lavage findings in patients with chronic nonproductive cough
}

\author{
L.P.A. McGarvey ${ }^{\star+}$, P. Forsythe*, L.G. Heaney ${ }^{+}$, J. MacMahon ${ }^{+}$, M. Ennis*
}

Bronchoalveolar lavage findings in patients with chronic nonproductive cough. L.P.A. McGarvey, P. Forsythe, L.G. Heaney, J. MacMahon, M. Ennis. (C)ERS Journals Ltd 1999. ABSTRACT: Mast cells and eosinophils may play a role in the pathophysiology of chronic cough in nonasthmatics. It is unknown, however, whether degranulation of these cells occurs in the airways of such patients.

Thirty-five nonsmoking patients referred with a chronic nonproductive cough (mean cough duration 76.2 months) were evaluated using a comprehensive diagnostic protocol. Bronchoalveolar lavage (BAL) cell differentials and BAL histamine, tryptase and eosinophilic cationic protein (ECP) concentrations were determined. Ten nonsmoking healthy volunteers served as controls.

Diagnostic subgroups were identified: eight postnasal drip syndrome (PNDS), seven cough variant asthma (CVA), seven gastro-oeseophageal reflux (GOR), seven dual aetiology and six idiopathic. Nonasthmatic coughers (NAC) were characterized as those patients without bronchial hyperresponsiveness on histamine challenge and whose cough had either responded to therapy for PNDS or GOR or failed to improve with antiasthma therapy. There was a significant increase in both eosinophil and mast cell numbers $(p<0.05)$ and in histamine levels $(p=0.027)$ when NAC patients were compared with controls. Tryptase and ECP levels were elevated in 7 of 23 and 6 of 23 NAC patients, respectively.

In conclusion, airway inflammatory cell numbers are not only increased but also activated, suggesting an important role for airways inflammation in the pathophysiology of chronic nonproductive cough.

Eur Respir J 1999; 13: 59-65.

\author{
*Dept of Clinical Biochemistry, The \\ Queen's University of Belfast, Belfast, \\ Northern Ireland, UK. 'Dept of Respira- \\ tory Medicine, Belfast City Hospital, \\ Belfast, Northern Ireland, UK. \\ Correspondence: L.P.A. McGarvey \\ Dept of Respiratory Medicine \\ Level 8 \\ Belfast City Hospital \\ Lisburn Road \\ Belfast BT9 7AB \\ Northern Ireland \\ UK \\ Fax: 441232263879
}

Keywords: Airway inflammation bronchoalveolar lavage chronic nonproductive cough inflammatory mediators

\section{Received: January 151998}

Accepted after revision July 251998

Supported by the Northern Ireland Chest, Heart and Stroke Association.
Chronic nonproductive cough (CNPC) is a common reason for referral to a respiratory physician and is associated with considerable morbidity. The pathophysiology of CNPC remains unclear; however, such individuals have increased sensitivity to a variety of inhaled tussive stimuli including capsaicin and solutions with low chloride concentrations [1]. Patients with cough following a viral infection [2] and asthmatic patients with cough [3] also demonstrate a heightened response to inhaled capsaicin, suggesting that airway inflammation may contribute to the pathophysiology of this disease.

Elevated numbers of eosinophils and metachromatic cells have been reported in expectorated sputum samples from nonasthmatic patients with a steroid-responsive cough [4]. BOULET et al. [5] described increased inflammatory cell numbers in bronchoalveolar lavage (BAL) fluid and airway inflammation in bronchial biopsy samples from nonasthmatic patients with CNPC when compared with controls. In addition, nearly half of the patients followed up reported symptom response to inhaled steroids, drugs which, in asthmatics, are known to decrease the numbers and activation status of airway inflammatory cells, including mast cells and eosinophils [6].

When inhaled, the inflammatory mediators histamine, bradykinin and prostaglandin $\mathrm{E}_{2}\left(\mathrm{PGE}_{2}\right)$ induce cough in normal subjects, although only $\mathrm{PGE}_{2}$ enhances the tussive effect of capsaicin [7]. Recently, the $\mathrm{H}_{1}$ receptor antagonist loratadine, which inhibits the release of histamine and leukotrienes produced by mast cells and eosinophils, has been shown to reduce cough induced by ultrasonically nebulized distilled water in nonasthmatic patients with chronic cough due to nasal disease [8]. To date, there have been no reports describing the state of activation of such pro-inflammatory cells and in particular the concentrations of their inflammatory mediators in the airways of patients with CNPC.

The aim of this study, therefore, was to identify whether mast cell and eosinophil degranulation occurs in the airways of nonasthmatics with CNPC by measuring airway concentrations of histamine and tryptase and eosinophil cationic protein (ECP) in BAL fluid.

\section{Methods}

\section{Subjects}

Thirty-five patients ( 23 female, median age 50 yrs, range 20-69 yrs) were studied. All patients had been referred to the cough clinic at Belfast City Hospital with a nonproductive cough persisting for more than 3 weeks as their sole respiratory symptom (mean duration 76.2 months, range 2-240 months). They were all lifetime nonsmokers and had normal results on chest radiography and spirometry. 
Patients with a previous history of other chest disease, any systemic disease, symptoms of an upper respiratory tract infection within the preceding 8 weeks or those taking angiotensin-converting enzyme inhibitors were excluded from the study.

Ten healthy subjects (three female, median age $36 \mathrm{yrs}$, range $25-59$ yrs) were recruited as negative controls. These individuals were also nonatopic, lifetime nonsmokers and had had no upper respiratory tract infection within the preceding 8 weeks.

The study was approved by the Research Ethics Committee of the Faculty of Medicine, The Queen's University of Belfast. Prior to taking part, written informed consent was obtained from all subjects.

\section{Patient evaluation}

The patients were investigated according to a diagnostic protocol based on that described by IRWIN et al. [9] and previously reported by the present authors [10]. In brief, after history and physical examination, an ear, nose and throat (ENT) examination was performed and graded by a consultant ENT surgeon, blinded to the patient's symptoms. A histamine challenge [11] and computed tomography (CT) scan of the sinuses in the coronal plane were performed. Atopy was defined as the presence of one or more specific serum immunoglobulin E (IgE) to four common inhaled allergens measured by a radioallergosorbent test (RAST) (Pharmacia Upjohn, Uppsala, Sweden).

Ambulatory $\mathrm{pH}$ monitoring of the oesophagus was performed using a Synectics Digitrapper Mark 11 (Irving, TX, USA). Analysis was performed using the EsopHgram Programme (Gastrosoft, Irving, TX, USA). Patients were identified as having abnormal reflux on 24-h oesophageal $\mathrm{pH}$ monitoring if they exceeded the 95 th percentile for per cent total time $\mathrm{pH}<4(>4.8 \%)$, per cent upright time with $\mathrm{pH}<4(>6.2 \%)$ and per cent supine time with $\mathrm{pH}<4$ $(>1.2 \%)$ for 20 normal volunteers [12]. A reflux episode began when the $\mathrm{pH}$ dropped below 4 and ended when the $\mathrm{pH}$ rose above this value. Cough and reflux episodes were deemed to bear a temporal relationship with one another if events occurred simultaneously or within $5 \mathrm{~min}$ of one another [13].

\section{Identification of diagnostic subgroups}

A suspected aetiology was based on history, examination and/or positive investigation, but was only accepted when the patient reported satisfactory improvement or complete resolution of cough after a period of diagnosisspecific therapy.

Cough variant asthma. A history of cough at night, during or following exercise, in cold air or precipitated by aerosols or sprays suggested cough variant asthma (CVA). A diagnosis of CVA was only accepted when patients with airway hyperresponsiveness (provocative concentration of histamine causing a $20 \%$ fall in forced expiratory volume in one second (PC20) $\leq 8 \mathrm{mg} \cdot \mathrm{mL}^{-1}$ histamine [11]) reported cough resolution or satisfactory improvement after asthma treatment.

Postnasal drip syndrome. A diagnosis of postnasal drip syndrome (PNDS) was considered when patients reported suggestive symptoms or had a positive ENT exam- ination or positive sinus CT scan [14], but was only accepted when the patient reported satisfactory improvement or complete resolution of cough after a period of intranasal anti-inflammatory and decongestant therapy.

Gastro-oesophageal reflux. A diagnosis of gastro-oesophageal reflux (GOR)-associated cough was considered if typical reflux symptoms were described or subjects had abnormal reflux on 24-h oesophageal $\mathrm{pH}$ monitoring [12], but was only accepted when cough improved or res-olved after antireflux treatment.

Idiopathic. Patients were identified as idiopathic if the cough persisted despite sustained therapy ( $\geq 4$ months) directed against the presumed cause or if the history was unremarkable and investigations normal, and the cough resolved spontaneously or failed to respond to empirical therapy for CVA, PNDS and GOR.

\section{Bronchoscopy and bronchoalveolar lavage}

All bronchoscopies were performed using a standardized protocol [15]. As any previously prescribed therapy for cough had been stopped before undergoing diagnostic evaluation, the patients had not been taking any medication for at least 2 months before the bronchoscopy. BAL was performed $(3 \times 60 \mathrm{~mL}$ aliquots of sterile isotonic saline, right middle lobe). The return samples were pooled, placed immediately on ice, taken to the laboratory and processed as described below.

\section{Bronchoalveolar lavage processing}

Volume return and total cell count were measured and differential cell counting was performed using the glass coverslip method [16] as described previously [15]. All counts were performed by an observer blinded to the patients' symptoms. Eosinophil cationic protein (ECP)/radioimmunoassay (RIA, Pharmacia Upjohn), histamine (RIA, Immunotech, Marseille, France) and tryptase (Unicap, Pharmacia Upjohn) were measured in the cell-free BAL supernatant using the commercially available kits.

\section{Statistics}

Results are reported as medians (range) as appropriate unless otherwise stated. Nonparametric tests were used throughout. Intergroup comparisons were made using the Mann-Whitney U-test. Where multiple Mann-Whitney Utests were required for subgroup analysis, the data were first analysed using Kruskal-Wallis one-way analysis of variance (ANOVA) and interpreted using Bonferroni's correction for multiple comparisons. Correlations were tested using Spearman's rank method. A value of $p<0.05$ was considered significant. Elevated levels of eosinophilor mast cell-derived mediators were defined as those greater than the mean +2 SD of the airway concentrations in the healthy control patients.

\section{Results}

\section{Subject characteristics and diagnostic subgroups}

The clinical characteristics of 35 patients with CNPC and 10 healthy controls are shown in table 1 . The 12 patients with CVA either alone or in combination with another cause constitute the group of asthmatic coughers (AC). 
Table 1. - Characteristics of the subjects

\begin{tabular}{|c|c|c|c|c|c|c|}
\hline $\begin{array}{l}\text { Diagnosis } \\
\text { (n) }\end{array}$ & $\begin{array}{l}\text { Sex } \\
\mathrm{M} / \mathrm{F}\end{array}$ & $\begin{array}{c}\text { Age } \\
\text { yrs } \\
\text { Mean } \pm \text { SD }\end{array}$ & $\begin{array}{l}\text { Cough duration } \\
\text { months } \\
\text { Mean (range) }\end{array}$ & $\begin{array}{l}\text { Atopy } \\
+/-\end{array}$ & $\begin{array}{c}\text { FEV1 \% pred } \\
\text { Median (range) }\end{array}$ & $\begin{array}{c}\mathrm{PC} 20 \\
\mathrm{mg} \cdot \mathrm{mL}^{-1} \\
\text { Mean (range) }\end{array}$ \\
\hline NAC (23) & $10 / 13$ & $46.7 \pm 13.9$ & $71.9(2-240)$ & $4 / 19$ & $109.0(91-139)$ & $>8$ \\
\hline $\mathrm{AC}(12)$ & $2 / 10$ & $53.5 \pm 10.1$ & $85.1(12-240)$ & $2 / 10$ & $88.0(80-130)$ & $3.72(0.04-7.8)$ \\
\hline Healthy controls $(10)$ & $7 / 3$ & $35.1 \pm 13.6$ & - & 0 & $114.0(89-132)$ & $>16$ \\
\hline
\end{tabular}

M: male; F: female; +: atopic (defined as presence of one or more specific serum immunoglobulin $\mathrm{E}$ to four common inhaled allergens measured by a radioallergosorbent tests (RAST)); -: nonatopic; FEV1: forced expiratory volume in one second; PC20: provocative concentration of histamine causing a $20 \%$ decrease in FEV1; NAC: nonasthmatic cough; AC: asthmatic cough.

The remaining 23 patients form the group of nonasthmatic coughers (NAC).

The results of the diagnostic protocol are shown in table 2. CVA was the sole diagnosis in seven patients, and eight patients had PNDS as the sole cause of cough (five with sinusitis, two with rhinosinusitis and one with rhinitis). Three of these patients did not describe symptoms characteristic of PNDS history but had evidence on clinical inspection and on CT imaging. Nine nonasthmatic patients with cough due to GOR (two in combination with PNDS)

Table 2. - Symptoms reported and outcome of investigations performed on 35 patients with chronic nonproductive cough

\begin{tabular}{|c|c|c|c|c|c|c|c|c|c|}
\hline \multirow[b]{2}{*}{ Diagnosis } & \multirow[b]{2}{*}{ Patient No. } & \multicolumn{2}{|c|}{ Symptoms } & \multirow[b]{2}{*}{$\begin{array}{l}\text { Histamine } \\
\text { challenge }\end{array}$} & \multicolumn{3}{|c|}{ 24-h oesophageal $\mathrm{pH}$ monitoring } & \multicolumn{2}{|c|}{ ENT assessment } \\
\hline & & PNDS & GOR & & $\begin{array}{l}\text { Significant } \\
\text { acid reflux }\end{array}$ & $\begin{array}{c}\text { Coughs } \\
n\end{array}$ & $\begin{array}{c}\text { Correlation } \\
\%\end{array}$ & $\begin{array}{l}\text { ENT } \\
\text { grade }\end{array}$ & $\begin{array}{r}\text { CT } \\
\text { scan }\end{array}$ \\
\hline \multirow{8}{*}{ PNDS } & 1 & + & + & - & $\mathrm{U}$ & $\mathrm{U}$ & $\mathrm{U}$ & 3 & + \\
\hline & 2 & - & + & - & - & 14 & 0 & 2 & + \\
\hline & 3 & + & - & - & - & 20 & 5 & 3 & + \\
\hline & 4 & - & - & - & - & 6 & 50 & 0 & + \\
\hline & 5 & - & - & - & - & 6 & 33 & 2 & + \\
\hline & 6 & + & - & - & - & 0 & 0 & 2 & + \\
\hline & 7 & + & + & - & U & $\mathrm{U}$ & $\mathrm{U}$ & 2 & + \\
\hline & 8 & + & - & - & - & 1 & 0 & 0 & - \\
\hline \multirow[t]{7}{*}{ GOR } & 9 & - & + & - & $\mathrm{U}$ & $\mathrm{U}$ & $\mathrm{U}$ & 0 & - \\
\hline & 10 & - & + & - & + & 5 & 20 & 0 & + \\
\hline & 11 & - & + & - & + & 3 & 33 & 0 & - \\
\hline & 12 & + & + & - & + & 0 & 0 & 0 & + \\
\hline & 13 & - & - & - & + & 20 & 65 & 0 & - \\
\hline & 14 & - & + & - & + & 4 & 50 & 0 & + \\
\hline & 15 & + & - & - & + & 7 & 86 & 1 & - \\
\hline \multirow[t]{6}{*}{ Idiopathic } & 16 & - & - & - & - & 20 & 10 & 0 & - \\
\hline & 17 & - & - & - & - & 2 & 0 & 0 & - \\
\hline & 18 & - & - & - & - & 5 & 20 & 0 & - \\
\hline & 19 & - & - & - & - & 21 & 24 & 1 & - \\
\hline & 20 & - & - & - & - & 7 & 0 & 0 & - \\
\hline & 21 & - & - & - & - & 6 & 0 & 0 & - \\
\hline \multirow[t]{2}{*}{ GOR/PNDS } & 22 & + & + & - & + & 9 & 45 & 3 & - \\
\hline & 23 & - & + & - & + & 0 & 0 & 0 & + \\
\hline \multirow[t]{7}{*}{ CVA } & 24 & - & - & + & - & 13 & 30 & 0 & - \\
\hline & 25 & + & + & + & + & 4 & 50 & 0 & - \\
\hline & 26 & + & + & + & + & 5 & 80 & 1 & + \\
\hline & 27 & - & + & + & + & 0 & 0 & 0 & - \\
\hline & 28 & - & - & + & - & 7 & 0 & 1 & + \\
\hline & 29 & - & - & + & - & 7 & 0 & 1 & - \\
\hline & 30 & + & - & + & - & 1 & 0 & ND & - \\
\hline CVA/PNDS & 31 & + & + & + & + & 81 & 19 & 0 & + \\
\hline CVA/PNDS & 32 & + & - & + & - & 13 & 15 & 2 & + \\
\hline CVA/PNDS & 33 & + & - & + & - & 18 & 28 & 1 & + \\
\hline CVA/GOR & 34 & - & + & + & + & 51 & 40 & 1 & - \\
\hline CVA/GOR & 35 & + & + & + & + & 3 & 33 & 0 & - \\
\hline
\end{tabular}

PNDS: postnasal drip syndrome; GOR: gastro-oesophageal reflux; ENT: ear, nose and throat; CT: computed tomography; CVA: cough variant asthma; Symptoms, +/-: present/absent; histamine challenge, +: concentration of histamine causing a $20 \%$ decrease in forced expiratory volume in one second $\leq 8 \mathrm{mg} \cdot \mathrm{mL}^{-1}$. Significant acid reflux, + : when data from $24-\mathrm{h} \mathrm{pH}$ monitoring exceeded the 95 th percentile for \% total time $\mathrm{pH}<4(>4.8 \%), \%$ upright time $\mathrm{pH}<4(>6.2 \%)$ and $\%$ supine time $\mathrm{pH}<4(>1.2 \%)$ obtained for 20 normal volunteers; \% correlation: \% of coughs occurring simultaneously or within 5 min following an acid reflux event; U: unsuccessful attempt to measure oesophageal $\mathrm{pH}$ owing to technical difficulty. ENT grades, 0 : no indication of postnasal drip; 1 : minimal irritation from postnasal drip; 2: mild irritation from postnasal drip; 3: marked irritation from postnasal drip; 4: marked irritation plus mucoid pooling. CT scan, +: coronal CT scan of the sinuses demonstrating mucosal thickening, air fluid level or sinus opacification. ND: not done. 
were identified, three of whom did not report symptoms suggestive of reflux. Oesophageal $\mathrm{pH}$ monitoring was technically unsuccessful in one patient; however, in the remaining eight, abnormal acid reflux was demonstrated. In five cases, symptom correlation with reflux events was $\geq 45 \%$ (table 2). A dual aetiology was accepted in seven individuals, with PNDS contributing with either GOR or CVA in five cases and in two patients cough was caused by CVA and GOR in combination. Idiopathic cough was diagnosed in six cases and, in two of these individuals, symptoms persisted despite courses of inhaled steroids and therapy directed at both PNDS and acid reflux. Three patients with idiopathic cough reported spontaneous resolution of cough after 6 months and one patient's cough resolved following inhaled steroids.

\section{Laboratory findings}

No difference was observed in lavage return or total cell counts between patients with either CNPC (70 mL (40-85) and $1.2 \times 10^{5}$ cells $\left.\cdot \mathrm{mL}^{-1}\left(0.5-2.8 \times 10^{5}\right)\right)$ or $\mathrm{AC}(70 \mathrm{~mL}$ $(45-90)$ and $1.3 \times 10^{5}$ cells. $\left.\mathrm{mL}^{-1}\left(0.6-3.8 \times 10^{5}\right)\right)$ and controls $\left(80 \mathrm{~mL}(55-120)\right.$ and $1.6 \times 10^{5}$ cells $\cdot \mathrm{mL}^{-1}(0.9$ $\left.2.3 \times 10^{5}\right)$ ).
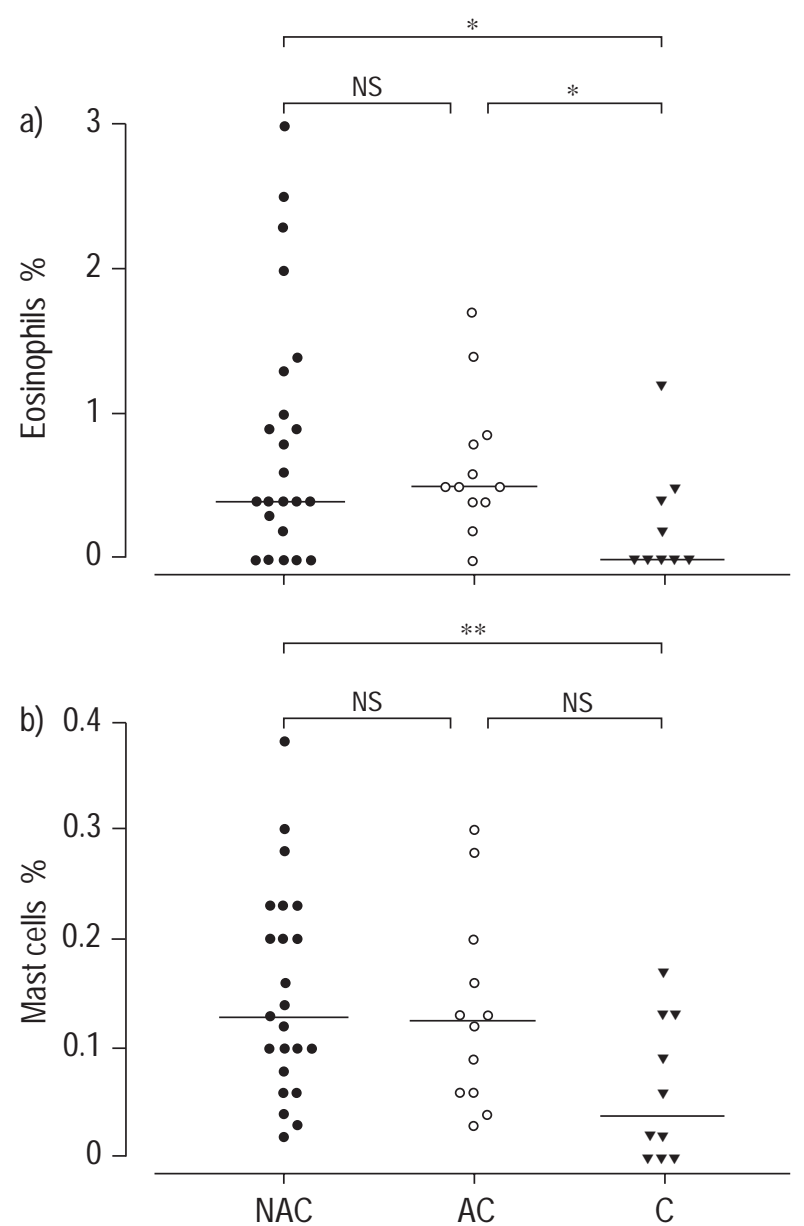

Fig. 1. - Comparison of the percentage of a) eosinophils and b) mast cells in the bronchoalveolar lavage from patients with nonasthmatic cough (NAC; $n=23)$, asthmatic cough $(A C ; n=12)$ and healthy control subjects $(C ; n=10)$. Individual results are shown and the lines represent the median percentage values. $*$ : $\mathrm{p}<0.05 ; * *$ : $\mathrm{p}<0.01$

\section{Differential cell counts}

When all patients with CNPC were considered as a group, there was a significant increase in the percentages of both eosinophils $(\mathrm{p}<0.05)$ and mast cells $(\mathrm{p}<0.01)$ compared with controls (data not shown). This observation persisted when patients with a nonasthmatic cough (NAC, $\mathrm{n}=23$ ) were compared separately against controls (fig. 1). There was a significant increase in eosinophil percentages compared with controls when all asthmatic patients (AC, $n=12$ ) were considered (fig. 1a). The increase in mast cell number in all patients with AC was similar to that in patients with NAC, although the difference from controls did not reach statistical significance, probably owing to the small number of cases in this group (fig. 1b).

Differential cell counts for diagnostic subgroups and controls are shown in table 3 . When compared with control subjects significant intergroup differences were observed. Eosinophil percentages were significantly increased in GOR patients only when compared with controls $(\mathrm{p}=0.003)$. Mast cell percentages were significantly higher in the idiopathic group $(\mathrm{p}=0.005)$ than in controls. Although mast cell percentages were doubled in the PNDS and dual sub-groups compared with controls, this did not reach statistical significance. Eosinophil and mast cell numbers in patients with CVA alone were elevated compared with controls but this did not achieve statistical significance. No statistically significant differences were found between the individual diagnostic subgroups, although increases in eosinophils in GOR and mast cells in the idiopathic group were observed when compared with each of the other subgroups. There was no difference in the other cells enumerated (macrophages, neutrophils, lymphocytes, and epithelial cells) between any of the groups.

Only six patients were atopic: one with GOR, two with $\mathrm{AC}$ and three with PNDS. Thus the role of atopy in the induction of airway inflammation in this group of patients with chronic nonproductive cough could not be assessed.

\section{Inflammatory mediators}

Histamine concentrations were significantly higher in CNPC patients than in controls $(p<0.05)$. This was also the case in the NAC group, even when the one subject with a very high histamine value was excluded $(\mathrm{p}=0.028)$ (fig. 2a). Histamine concentrations were not increased in the asthmatic group compared with controls, although 5 of 12 patients had elevated levels (defined as greater than the mean \pm 2 sD of the control airway concentration). Tryptase concentrations were not significantly raised in CNPC patients when compared with controls, although elevated concentrations were found in 7 of 23 NAC patients and 4 of 12 patients with $\mathrm{AC}$ (fig. 2b). Histamine and tryptase concentrations were significantly correlated $(\mathrm{r}=0.581, \mathrm{p}=$ 0.0057). Elevated levels of ECP were measured in six NAC patients and five AC patients (fig. 2c). No significant differences were found in airway mediator levels between cough subgroups.

\section{Discussion}

This study demonstrates an increase in inflammatory cells (mast cells and eosinophils) in BAL fluid from patients with CNPC compared with healthy controls. This 
Table 3. - Inflammatory cells in bronchoalveolar lavage (\% of total cell count)

\begin{tabular}{lccrrrr}
\hline & $\begin{array}{c}\text { PNDS } \\
\mathrm{n}=8\end{array}$ & $\begin{array}{c}\mathrm{GOR} \\
\mathrm{n}=7\end{array}$ & \multicolumn{1}{c}{$\begin{array}{c}\text { Idiopathic } \\
\mathrm{n}=6\end{array}$} & $\begin{array}{c}\text { Dual } \\
\mathrm{n}=6\end{array}$ & \multicolumn{1}{c}{$\begin{array}{c}\text { CVA } \\
\mathrm{n}=7\end{array}$} & $\begin{array}{c}\text { Healthy controls } \\
\mathrm{n}=10\end{array}$ \\
\hline Macrophage & $84.3(71.7-93.0)$ & $85.0(65.0-93.9)$ & $77.5(72-92.2)$ & $73.4(36.8-94)$ & $75.2(60.3-88)$ & $86.9(70-96.8)$ \\
Lymphocytes & $4.6(1.2-15.0)$ & $3.0(0.75-14.0)$ & $6.5(1.9-20.0)$ & $7.31(0.38-20.4)$ & $7.3(3-28.9)$ & $4.5(0.34-15)$ \\
Neutrophils & $2.7(1.0-6.8)$ & $6.2(0.7-17.0)$ & $2.7(0.8-13.9)$ & $12.5(2.8-47.1)$ & $3.0(1.5-28.8)$ & $3.2(0.6-8.7)$ \\
Epithelial & $6.5(1.0-18.0)$ & $3.0(0.75-14.0)$ & $5(3.0-15.9)$ & $6.7(0.2-15.5)$ & $7.0(1-10.5)$ & $2.6(0.4-16)$ \\
Eosinophils & $0.1(0-3.0)$ & $1.0(0.4-2.3)^{\#}$ & $0.4(0-0.9)$ & $0.6(0.2-2.5)$ & $0.5(0-1.4)$ & $0(0-1.2)$ \\
Mast cells & $0.15(0.03-0.2)$ & $0.08(0.02-0.2)$ & $0.26(0.1-0.4)^{+}$ & $0.12(0.09-0.2)$ & $0.13(0.03-0.3)$ & $0.06(0-0.2)$ \\
\hline
\end{tabular}

Data are presented as median (range). PNDS: postnasal drip syndrome; GOR: gastro-oesophageal reflux; CVA: cough variant asthma; Dual: three patients with PNDS/CVA, two patients with PNDS/GOR and two patients with CVA/GOR. \#: p=0.003 (eosinophils; GOR versus controls); ${ }^{+}: \mathrm{p}=0.005$ (mast cells; idiopathic versus controls).

was also true in the NAC group and in 14 of $23(61 \%)$ such patients elevated levels of mast cell and/or eosinophil-derived mediators were detected in the airways. Although elevated mediator levels were not found in all patients with cough it is recognized that airway inflammation is a dynamic process and the sampling at bronchoscopy reflects events occurring at one time point only.

Using the diagnostic protocol described above, a clear aetiology was identified in 29 of 35 (83\%) patients and in agreement with the work by IRwIN et al. [9], which first described the anatomic diagnostic protocol, CVA, PNDS and GOR, either alone or in combination, accounted for the cough in most patients. Each aetiology was confirmed after resolution or satisfactory improvement in the cough with diagnosis-specific therapy. Therefore, although some patients had significant oesophageal reflux on 24-h $\mathrm{pH}$ monitoring, they were not categorized as GOR because the cough failed to respond to maximal antireflux therapy or responded to an alternative therapy. In these individuals, acid reflux may coexist with rather than contribute to the cough. Despite this comprehensive evaluation, no clear aetiology was apparent in six patients and symptoms persisted in two despite multiple courses of intensive therapy.

A characteristic feature in the pathogenesis of asthma is airway inflammation. The mast cell [17] and the eosinophil [18] are considered to play crucial roles in the production of airway inflammation, which is associated with bronchial hyperreactivity and acute episodes of asthma. The eosinophil and mast cell percentages reported in patients with chronic nonproductive cough were of the same order as those in subjects with mild classical asthma reported in the literature $[19,20]$.

The concept of airway inflammation in the absence of characteristic abnormalities of asthmatic lung function is now recognized. GIBSON and coworkers $[4,21]$ reported increased numbers of both metachromatic cells and eosinophils in expectorated sputum from nonasthmatic patients with steroid-responsive cough. Induced sputum eosinophilia has also been reported recently in atopic patients with bronchodilator-resistant cough [22]. In the study by BOULET et al. [5], BAL cell differentials between nonasthmatic patients with chronic cough and controls differed mainly in metachromatic and epithelial cells. In contrast, no significant contribution from epithelial cells was observed in the present study. BAL represents both airway and alveolar compartments and the findings using this sampling method, taken together with the previously reported studies using expectorated and induced sputum, suggest that airway inflammation in nonasthmatic cough may be distributed throughout the bronchial tree.

In addition to the enumeration of inflammatory cells, markers of their activation are important. ECP is one of the most potent tissue-damaging proteins released by the eosinophil and its destructive effect on airway epithelium and surrounding tissues may expose underlying sensory nerves and cough receptors to a wide range of environmental insults. Although not a consistent feature among patients with cough, the raised levels of ECP noted in six patients with nonasthmatic cough provide some support for the pathological role of the eosinophil and its mediators. There have been no reports to date characterizing the nature of inflammation in the airways of patients with CVA; however, five of 12 such patients had raised levels of ECP and six had elevated histamine and/or tryptase concentrations. These mediators may contribute to the airway hyperreactivity characteristic of CVA; however, the failure to demonstrate consistent elevation of inflammatory cells in the airways from patients with CVA alone suggests that CVA may represent the mild end of the clinical spectrum of asthma. The variation observed in the mediator concentrations may also be due to the fact that the intensity of cough symptoms at the time of bronchoscopy and BAL varied between patients. It was not possible to control for such variation in this study. In addition, contamination of the bronchoscopy biopsy channel with upper airway material is possible; during the procedure care was taken to minimize suction until the bronchoscope was below the vocal cords. Furthermore, although bacteria are known to generate histamine [23], no subject had evidence of infection at the time of bronchoscopy, therefore such a non-mast cell source of histamine was considered unlikely.

Cough arising from PNDS is not solely related to mechanostimulation of pharyngeal or laryngeal receptors. Histamine inhalation causes cough [7] and recent clinical evidence suggests that the $\mathrm{H}_{1}$ antagonist loratadine reduces chronic cough owing to nasal disease, presumably by its action on the $\mathrm{H}_{1}$ receptor or by inhibiting the mediator release from mast cells [8]. Bradykinin, which is also tussive when inhaled, is formed from its precursor kininogen and tryptase is known to catalyse this process. Elevated levels of histamine and tryptase were measured in the lavage fluid of five and three of the eight patients with PNDS, respectively. Such mediators may contribute to the upper airway hyperresponsiveness described in these patients [24]. This extrathoracic airway dysfunction is thought to account for asthma-like symptoms, particularly 

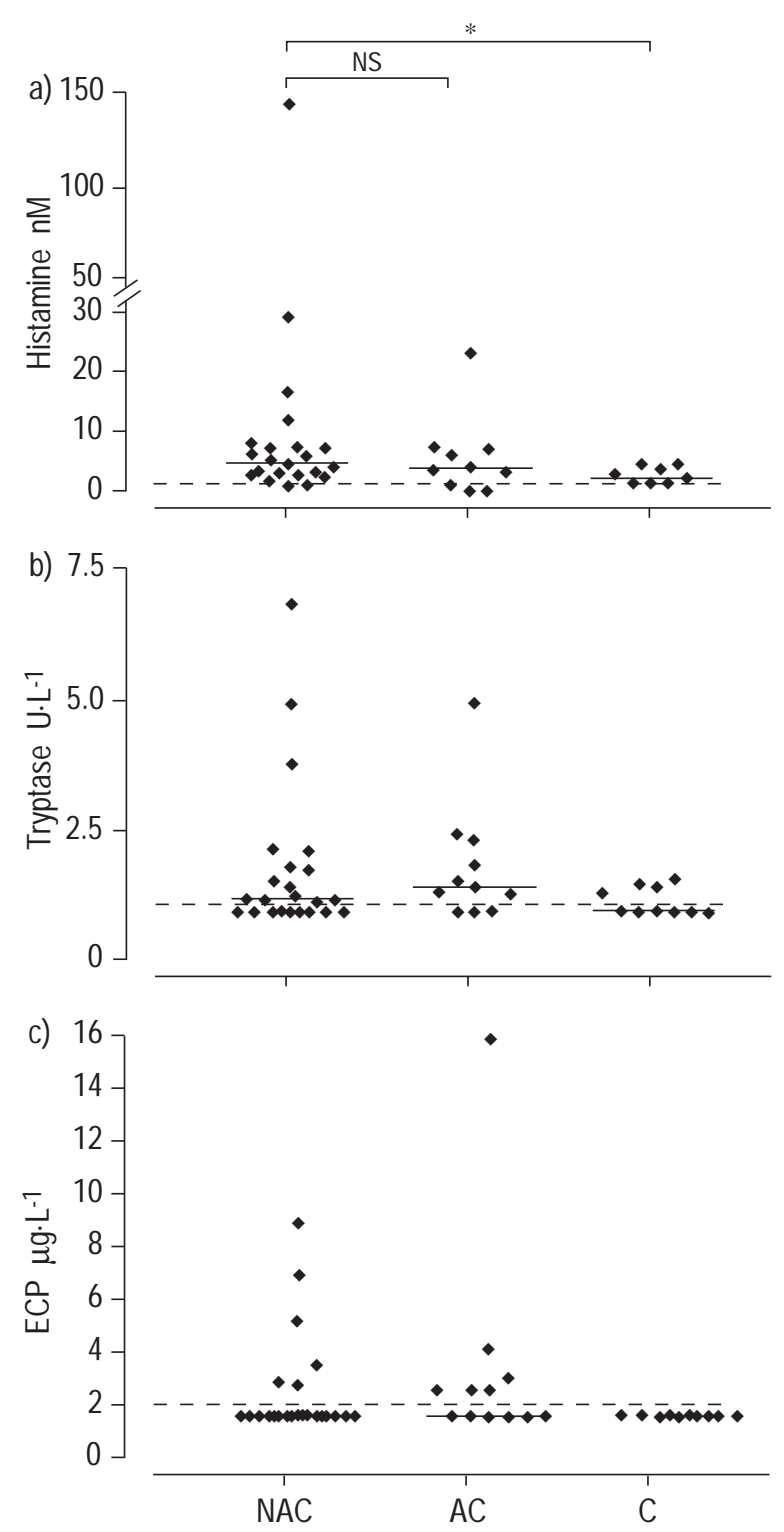

Fig. 2. - Concentrations of a) histamine, b) tryptase and c) eosinophil cationic protein (ECP) in the bronchoalveolar lavage fluid from patients with nonasthmatic cough (NAC; $n=23)$, asthmatic cough $(A C ; n=12)$ and healthy control subjects $(C ; n=10)$. Individual results are shown and the lines represent the median values. The dotted lines represent the limit of detection for the assays. ${ }^{*}: \mathrm{p}<0.05$.

chronic cough [25]. Furthermore, since histamine and tryptase concentrations correlate, the metachromatic cells counted are most probably mast cells, as basophils contain almost no tryptase.

This is the first report of increased eosinophil numbers in the airway lavage from patients with GOR-associated cough. These findings are supported by the recent report of elevated eosinophil numbers and ECP in induced sputum obtained from patients with chronic cough and GOR [26]. Eosinophilic bronchitis in nonasthmatic patients with chronic cough was first described by GIBSON et al. [4] and although the cough in these patients responded to steroids, it is apparent from the present study that not all patients with chronic cough and a predominant eosinophil component to their airway inflammation require steroid therapy. The mechanism underlying GOR-associated cough has not been defined and both reflux with aspiration or a neural reflex have been considered [27]. In this study, at bronchoscopy, there was no evidence of macroaspiration in any patient, although microaspiration could not be excluded. A recent study in a group of 30 cough patients, which used the measurement of lipid-laden macrophages in sputum as a marker for aspiration, found no evidence to support such a mechanism [28]. The concept of acid stimulation of distal oesophageal receptors activating an oesophageal-tracheobronchial reflex has gained wider support [29]. The lung and the gut, having a common embryological origin, share a similar neural supply, the vagus nerve, and recent studies have described neurogenic inflammation in the lungs of guinea-pigs after instillation of acid into the distal oesophagus [30]. Biopsy of skin after calcitonin gene-related peptide injection reveals an eosinophilic infiltration [31] and it is recognized that substance $P$ has a degranulating effect on eosinophils [32]. Both of these neuropeptides participate in neurogenic inflammation and may play a role in the mechanism underlying the general pattern of eosinophilic recruitment to the airways which was observed in the GOR subgroup of coughers. This eosinophilic inflammation may directly provoke cough which, as suggested by ING et al. [33] may precipitate further acid reflux, so establishing a self-perpetuating, positive feedback cycle between cough and reflux.

A unifying theme in CNPC, regardless of aetiology, is the demonstration of an enhanced tussive response to capsaicin [1]. It is possible that this sensory hyperresponsiveness of the cough reflex is partly due to the presence of airway inflammation similar to that described in this paper. In support of this, it has been observed that the successful treatment of cough, which often includes anti-inflammatory therapy, is associated with a reduction in the tussive sensitivity to capsaicin $[10,34]$.

The present study population was a highly selected group. However, the authors feel that such a group is typical of those patients frequently referred to tertiary clinics and who often pose the greatest treatment difficulties. Furthermore, by considering the nonasthmatic coughers separately, the existence of airway inflammation in the absence of airway hyperresponsiveness has been reinforced. Finally, it is not clear whether the mechanical effect of persistent coughing alone can result in airway inflammation. However, in six individuals (patients numbers 3, 16, 19-22) with cough for a considerable duration (median 22 months (range 3-240 months)), no increase in inflammatory cells or elevation in inflammatory mediator concentrations was detected. This provides some anecdotal evidence that the mechanical effects of coughing do not explain fully the inflammation generally observed. The precise relationship between airway inflammation and the mechanism of cough will only be confirmed by the study of inflammatory parameters both at baseline and following successful therapy.

In summary, in a carefully evaluated group of both asthmatic and nonasthmatic patients with chronic nonproductive cough, increased numbers of eosinophils and mast cells in the airways were confirmed and, for the first time, elevated levels of their inflammatory mediators were demonstrated in the majority of individuals, supporting the role of these cells in the pathophysiology of this troublesome symptom. 
Acknowledgements. The authors gratefully acknowledge support from the estate of the late Mrs Youens, and would like to thank the staff in the bronchoscopy suite and J. Megarry in the pulmonary function laboratory at the Belfast City Hospital for their co-operation and assistance. B. Johnston, J. Lawson and C. Scally are thanked for their help with the diagnostic evaluation of the patients. V. Brown and B.C. Schock are thanked for their assistance with the mediator assays and I. Murray for her secretarial help.

\section{References}

1. Choudry NB, Fuller RW. Sensitivity of the cough reflex in patients with chronic cough. Eur Respir J 1992; 5: 296-300.

2. Stone RA, Barnes PJ. Patients with cough have increased sensitivity to low chloride and capsaicin solutions compared to normal and asthmatic subjects. Respir Med 1992; 86: 78. (Abstract.)

3. O'Connell F, Thomas VE, Studham JM, Pride NB, Fuller RW. Capsaicin cough sensitivity increases during upper respiratory infection. Respir Med 1996; 90: 279-286.

4. Gibson PG, Dolovich J, Denberg JA, Ramsdale EH, Hargreave FE. Chronic cough: eosinophilic bronchitis without asthma. Lancet 1989; i: 1346-1348.

5. Boulet LP, Millot J, Boulet M. Airway inflammation in non-asthmatic subjects with chronic cough. Am J Respir Crit Care Med 1994; 149: 482-489.

6. Djukanovic R, Wilson JW, Britten KM, et al. The effect of an inhaled corticosteroid on airway inflammation and symptoms in asthma. Am Rev Respir Dis 1990; 145: 669674.

7. Choudry NB, Fuller RW, Pride NB. Sensitivity of the human cough reflex: effect of inflammatory mediators prostaglandin $\mathrm{E}_{2}$, bradykinin, and histamine. Am Rev Respir Med 1989; 140: 137-141.

8. Tanaka S, Hirata K, Kurihara N, Yoshikawa J, Takeda T. Effect of loratadine, a $\mathrm{H}_{1}$ antihistamine, on induced cough in non-asthmatic patients with chronic cough. Thorax 1996; 51: 810-814.

9. Irwin RS, Curley FJ, French CL. Chronic cough: the spectrum and frequency of causes, key components of the diagnostic evaluation and outcome of specific therapy. Am Rev Respir Dis 1990; 141: 640-647.

10. McGarvey LPA, Heaney LG, Lawson JT, et al. Evaluation and outcome of patients with chronic non productive cough using a comprehensive diagnostic protocol. Thorax 1998; 53: 738-743.

11. Cockcroft DW, Killin DN, Malon JA, Hargreave FE. Bronchial reactivity to inhaled histamine: a method and clinical survey. Clin Allergy 1977; 7: 235-240.

12. Johnston BT, McFarland RJ, Collins JSA, Love AHG. The symptom index: a useful marker of gastro-oesophageal reflux disease. Br J Surg 1992; 79: 1054-1055.

13. Ing AJ, Ngu MC, Breslin ABX. Chronic persistent cough and gastro-oesophageal reflux. Thorax 1991; 46: 479483.

14. Shapiro GG, Rachelefsky GS. Introduction and definition of sinusitis. J Allergy Clin Immunol 1992; 3: 417-418.

15. Heaney LG, Cross LJM, Standford CF, Ennis M. Substance $\mathrm{P}$ induces histamine release from pulmonary mast cells. Clin Exp Allergy 1995; 25: 179-186.

16. Laviolette M, Carreau M, Coulombe R. Bronchoalveolar lavage differential on microscope glass cover. Am Rev Respir Dis 1988; 138: 451-457.
17. Casale TB, Wood D, Richerson HB, Zehr B, Zavala D, Huninghake GW. Direct evidence of a role for mast cells in the pathogenesis of antigen induced bronchoconstriction. J Clin Invest 1987; 80: 1507-1511.

18. Gleich GJ. The eosinophil and bronchial asthma: current understanding. J Allergy Clin Immunol 1990; 85: 422 428.

19. Wardlaw AJ, Dunnette S, Gleich GJ, Collins JV, Kay AB. Eosinophils and mast cells in bronchoalveolar lavage in subjects with mild asthma. Am Rev Respir Dis 1988; 137 : 62-69.

20. Liu MC, Bleeker ER, Lichtenstein LM, et al. Evidence for elevated levels of histamine, prostaglandin $\mathrm{D}_{2}$, and other bronchoconstricting prostaglandins in the airways of subjects with mild asthma. Am Rev Respir Dis 1990; 142: 126-132.

21. Gibson PG, Hargreave FE, Girgis Gabardo A, Morris M, Denberg JA, Dolovich J. Chronic cough with eosinophilic bronchitis: examination for variable airflow obstruction and response to corticosteroid. Clin Exp Allergy 1995; 25: 127-132.

22. Fujimura M, Songur N, Kamio Y, Matsuda T. Detection of eosinophils in hypertonic saline-induced sputum in patients with chronic nonproductive cough. J Asthma 1997; 34: 119-126.

23. Sheinman BD, Devalia JL, Davies RJ, Crook SJ, Tabaqchali S. Synthesis of histamine by Haemophilus influenzae. BMJ 1986; 292: 857-858.

24. Bucca C, Rolla G, Scappaticci E, et al. Extrathoracic and intrathoracic airway responsiveness in sinusitis. J Allergy Clin Immunol 1995; 95: 52-59.

25. Bucca C, Rolla G, Brussino L, De Rose L, Bugiani M. Are asthma-like symptoms due to bronchial or extrathoracic airway dysfunction? Lancet 1995; 346: 791-795.

26. Micheletto C, Burti E, Mauroner L, Pomari C, Turco P, Dal Negro R. Induced sputum and serum inflammatory markers in subjects with cough due to gastro-esophageal reflux. Eur Respir J 1997; 10: 317s. (Abstract.)

27. Harding SM, Richter JE. The role of gastroesophageal reflux in chronic cough and asthma. Chest 1997; 111: 1389-1402.

28. Carney IK, Gibson PG, Murree-Allen K, Saltos N, Olson LG, Hensley MJ. A systematic evaluation of mechanisms in chronic cough. Am J Respir Crit Care Med 1997; 156: 211-216.

29. Ing AJ, Ngu MC, Breslin ABX. Pathogenesis of chronic persistent cough associated with gastro-oesophageal reflux. Am J Respir Crit Care Med 1994; 149: 160-167.

30. Hamamoto J, Kohrogi H, Kawano O, et al. Eosophageal stimulation by hydrochloric acid causes neurogenic inflammation in the airways in guinea pigs. $J$ Appl Physiol 1997; 82: 738-745.

31. Pietrowski W, Foreman JC. Some effects of calcitonin gene-related peptide in human skin and on histamine release. Br J Dermatol 1986; 114: 37-46.

32. Kroegel C, Giembycz MA, Barnes PJ. Characterization of eosinophil activation by peptides. Differential effects of substance P, melittin and f-Met-Leu-Phe. J Immunol 1990; 145: 2581-2587.

33. Ing AJ, Ngu MC, Breslin ABX. Pathogenesis of chronic persistent cough associated with gastroesophageal reflux. Am J Respir Crit Care Med 1994; 149: 160-167.

34. O'Connell F, Thomas VE, Fuller RW, Pride NB. Cough sensitivity to inhaled capsaicin decreases with successful treatment of chronic cough. Am J Respir Crit Care Med 1993; 150: 374-380. 